\title{
Reprinted from \\ Proceedings of the Nutrition Society \\ Volume 40 (2), 195-207, 1981 \\ Sixth Boyd Orr Memorial Lecture
}

\author{
JC Waterlow* \\ Department of Human Nutrition, London School of Hygiene and Tropical Medicine, UK
}

The editor has asked me to write a few words to update my views and impressions on how much progress we have made since this lecture was given 25 years ago. When I returned from my post in Jamaica in 1972 to succeed BS Platt in the chair of Human Nutrition at the London School of Hygiene and Tropical Medicine, there were only two professors of Nutrition in England - I am not sure about Scotland - my chair and that of John Yudkin at Queen Elizabeth College (now part of King's). Moreover, we were the only school of Public Health in Europe that had a department of Nutrition. Now, as shown by the Group of Professors of Nutrition, the original number has multiplied almost 10-fold. My plan, at the London School of Hygiene and Tropical Medicine, was to build up a department which stood on four legs metabolism; clinical nutrition; public health nutrition; and nutrition policy. Now these subdivisions have tended, quite naturally, to become separate, indicating the multidisciplinary nature of nutrition. The Giessen Declaration $^{1}$ has reminded us that environmental science should be included in nutrition's field of interest. This diversity was implicitly recognised by Alan Jackson when he established the Institute of Human Nutrition at Southampton, recognising the unreality of treating nutrition as the prerogative of a single university department. Nevertheless, although I am probably biased, I still think that physiology and biochemistry, with the emerging discipline of molecular nutrition, are fundamental, because without them the other branches of nutrition will not be soundly based.

Twenty-five years ago it was already becoming clear that distinction must be made between nutrition as a science and nutrition as a profession. Steps were taken, through the good auspices of Ann Walker of Reading University and the Institute of Biology, to establish criteria for a recognised nutritionist and this very important objective has now been achieved.

I think it is clear that the crisis of which I wrote 25 years ago has now been overcome, and that nutrition is now firmly established, both as a science and, in its applications, as a professional activity.

Professor John Waterlow

\section{Reference}

1 The Giessen Declaration. Public Health Nutrition 2005; 8(6A): $783-6$. 
The sixth Boyd Orr Memorial Lecture, organized by the Boyd Orr Memorial Trust, was held at the University of Glasgow, on 30 September r980

\title{
SIXTH BOYD ORR MEMORIAL LECTURE
}

\section{Crisis for nutrition}

\section{By J. C. Waterlow, Department of Human Nutrition, London School of Hygiene and Tropical Medicine}

\begin{abstract}
Almost exactly 100 years ago, in fact on 23 September, 1880 , John Boyd Orr was born quite near here, at Kilmaurs, Ayrshire. It is fitting that this lecture should be given in the University of Glasgow with which he had such close relations, first as a student and research assistant, and later as Rector and finally Chancellor. I think that the best way of paying tribute to this remarkable man in the centenary year of his birth is to see how his career, his achievements, even his failures, and not least his character, relate to the problems we face in nutrition today. This is a hard task, and I can only touch on a few points. Unlike many of the previous lecturers I never had the opportunity of meeting or knowing Boyd Orr. I have therefore had to rely on his own writings and on the very detailed memoir of him by Kay (1972), which is not only a mine of information but a fascinating and readable account of the successive stages of Boyd Orr's career. Some of you here knew him well and worked with him, and are therefore far better qualified to talk of him than I am. Yet in the long run what matters is the inspiration he provided to those who follow after, who could not know him, and it is these followers whom I must try to represent today.
\end{abstract}

\section{Lessons for us of Boyd Orr's career}

One of the first things that struck me was Boyd Orr's capacity for moving to where the action is and for getting himself into situations where he could use his special talents to the best advantage. As you will know, he graduated twice from this University, first as a teacher and then as a doctor. At the end of World War I he had the unique distinction, according to Kay, of being at the same time in the Army and the Navy. This is perhaps a foretaste of his remarkable ability to bridge gaps between different activities and disciplines, as he did later between animal and human nutrition and between nutrition and politics. As an Army doctor in World War I he was twice decorated for gallantry. This seems to me a symbol of another characteristic which stands out when one reads Boyd Orr's work-his courage, moral and intellectual as well as physical. The value he put on these qualities in others comes out very clearly in the memorial lecture he gave for the Independent Labour Party MP James Maxton, under the title, The role of the rebel in society (Orr, 195I). There was no belief or institution which Orr did not dare to challenge when he thought it right to do so. 
The third characteristic which I want to emphasize is that, although often described as an idealist, Boyd Orr was clearly a very practical man. There are hundreds of examples of this in the account of his life. I have the impression that he regarded scientific research as a means to an end. As Director of the Rowett Research Institute his job was the practical improvement of animal nutrition, and it is obvious that he saw it in that way, since many of his papers and lectures in the 1920 s and $30 s$ were addressed to farmers and to those actually engaged in animal husbandry.

Here I am particularly concerned with his contributions to human nutrition. Thomson, in the fourth lecture of this series (Thomson, 1978), has told us how his studies on the nutrition of children came about in a rather roundabout way, from a request by the Government for advice on the disposal of surplus milk. His advice was to feed it to the children of the poor, and his first paper on the subject-Milk consumption and the growth of school children-was published in the Lancet in I928 (Orr, 1928). This was followed by the surveys and feeding trials which Thomson has described, culminating eight years later in the classical book Food, Health and Income (Orr, 1936). However, as far as I have been able to find, the first publication of Boyd Orr's which deals specifically with human nutrition predates the work on school children. This is a paper, published in 1927 , on The nutritional condition of the East African native (Orr \& Gilks, 1927). Orr's interest in this subject seems to have been aroused as a side-effect of a tour he undertook in Africa to advise on the improvement of pastures deficient in minerals. Characteristically, this interest was not allowed to drop; it led to the organization of a series of studies on human nutrition in Kenya, summarized four years later in the famous report by Orr \& Gilks (193 I), of which the highlight is the comparison between the Masai and Kikuyu tribes. The early years of the r 930 set the pattern for the future development of Boyd Orr's work. His first publication which deals explicitly with the public health aspects of nutrition was the Chadwick lecture of 1934 on The National Food Supply and its Influence on Public Health (Orr, 1934). $\mathrm{He}$ described it at the time as in some respects the most important political and social question of the present day', and this question, in one form or another, was to be the main theme of his work for the rest of his life.

I have emphasized these dates for a reason. The early thirties, when Boyd Orr's attention was becoming concentrated on the economic and social as well as the scientific problems of nutrition, both at home and overseas, represent a watershed in our subject. On the one hand, the scientific advances in nutrition, particularly in our knowledge about essential amino acids and vitamins, led to a kind of euphoria, so that a leading American textbook of nutrition at that time could state in its preface that the nutritional problems of the world were all but solved. On the other hand, those years saw the first description in the English literature of kwashiorkor by Cicely Williams (1935) and the rapid realization that this was a very common disease throughout the under-developed world. At the same time, a Government committee, of which my predecessor B. S. Platt was secretary, was working on a two-volume report on Nutrition in the Colonial Empire (Economic Advisory 
Council, 1939), which showed to those who looked beyond the laboratory that all was far from well with nutrition in the world.

Boyd Orr seems to have approached these problems with characteristic courage and optimism, as shown by these quotations from that period:

'If we can avoid war and social disturbances, fifty years hence the community will enjoy a state of health and social amenities which so far have existed only in the imagination of the great social pioneers like Sir Edwin Chadwick.' (Orr, 1934),

and in a lecture to the British Association on the Economics of diet,

'There never was a time when there was more abundant goodwill' (towards a new National Food Policy) (Orr, 1935).

Paradoxically, it was precisely during the war that a National Food Policy was both possible and successful in the UK-a success to which Boyd Orr made a valuable contribution. It was after the war that the real difficulties began. I do not propose to describe in any detail his efforts to promote policies and actions in the international scene during the five years from the Hot Springs Conference in 1943 to his resignation as Director-General of the Food and Agriculture Organization in 1948. Other Boyd Orr lecturers, Boerma (1975) and Correa (1977), have done this better than I can. It seems clear from what they have said, that although Boyd Orr's proposals for a World Food Board were frustrated by lack of political will on the part of governments, his initiatives still have life in them. Although they may have been dismissed at the time as the dreams of an idealist, in fact they reflect the sound practical sense which characterized all his activities.

I have made these reflections on Boyd Orr's career partly because I want, on his anniversary, to try to recapture something of its essence; partly because it provides a necessary background to the theme I am trying to develop, to which I have given the title Crisis for nutrition.

\section{Why is there a crisis for nutrition?}

I am not referring by this title to the critical nutritional state of a large proportion of the world's population, but to the critical state of the subject. The problem is a crisis of identity for the nutritionist: what is he trying to do? We need not waste time discussing whether nutrition is a science or discipline in its own right, distinguishable from other branches of science. Some very authoritative opinions have proposed that it is not, for example Garry (1955): 'It is doubtful if nutrition is a science in the common sense of the word ... it is wise to regard it as a meeting place of the sciences and of scientists rather than a single scientific discipline.' and Blaxter (1979): 'There is a real difficulty at present in defining in any precise way what constitutes the field of endeavour in nutrition, let alone priorities within it, for there is a nutritional component in virtually every branch of biology and medicine.'

I used to agree with this point of view, but now I consider that it is incomplete, for reasons which I hope will emerge as we go along.

Many of us think of nutrition as in the main an applied subject, yet we would 
reject the idea that it has no basic scientific content. Again, however, it would be useless to embark on the well-worn discussion about whether or not there is any essential difference between basic and applied science or whether our subject has some characteristic mix of the two. As has been well said by Rivers (1979) in connection with research: 'To discuss research strategies without considering the researcher is to omit a crucial element from the debate'. The work, of whatever kind it be, is done by people, and people have different motives for what they do: on the one hand an interest in intellectual enquiry, on the other the desire to make a practical contribution, often, rather oddly, called 'idealism'. We might call them the motives of the head and the heart. This diversity of motives affects both the individual and the subject. It can be a source of strength and drive, as it obviously was for Boyd Orr; but it can also be a painful affliction for the individual and a danger to the credibility of the subject, if concern for suffering leads us to make diagnoses or propose solutions which are not based on sound knowledge. This pull in two directions is not, of course, confined to nutrition, but it seems to be particularly severe in our subject.

Then comes a second dilemma. When the nutritionist has come to terms with the conflict of motives, he then has to translate his aims into some kind of activity. Here he or she finds himself squeezed from two sides. (I realize that I am in danger of mixing metaphors; anyone who is simultaneously pulled and squeezed is in a bad situation, but these are the best words I can find to explain what I mean). On the one hand, if he aims to be a scientist, he becomes in effect a biochemist or a physiologist. If he is working in the clinical field he finds that in this country clinical nutrition is not recognized as a speciality in medicine-a situation which has serious implications for his career. As with any new subject, the people who have built up nutrition come from other disciplines, so why should there be any change? Indeed, I know of people who are making important contributions to nutrition, who regard with distaste the idea of having the label 'nutritionist' attached to them, as I did myself until some years ago.

The Neuberger Report (ARC/MRC, 1974) has been blamed for promoting this attitude: that nutrition is scientifically respectable only in so far as it is a branch of biochemistry or physiology. I think this reproach is unjustified, because the terms of reference of the Neuberger Committee were not to survey the whole scope of nutrition as a subject but to advise the Research Councils on research which it would be appropriate for them to support. In doing this the report laid particular stress on the need for work at the level of the whole animal, and did not neglect the epidemiological approach to problems of the community. Nevertheless, 6 years later it must be confessed that anyone wishing to work in human nutrition might be well advised to do his work under a different label. This, of course, is not true in animal nutrition.

The squeeze from the other side is based on the view that real progress in eliminating malnutrition can only come through social, economic and political change; that the kind of practical nutritional programmes which have been attempted are just patching up cracks; and that the most useful contribution of the 
nutritionist is to define more clearly the characteristics of communities at risk and to provide the planners with a choice of options. Thus the pressure on one side to operate as a biochemist or physiologist is balanced by pressure on the other to operate as a sociologist, demographer or political scientist.

The traditional view is that the names are unimportant, provided that the work gets done. My contention, on the contrary, is that it is important for nutrition somehow to achieve an identity of its own. It may be thought that I am exaggerating in speaking of a crisis for the subject, but if we look at our institutions, what do we find? In the United Kingdom, university departments of nutrition, as opposed to food technology, can be counted on the fingers of one hand, and none of them is in Scotland. It is instructive also to consider the United Nations organizations. I confess that I was astonished, when I read the first Boyd Orr lecture by Dr Boerma, the previous Director-General of FAO, on the subject The thirty years war against hunger, to find at the very end the following paragraph, which precisely illustrates my theme:

'I cannot end without reference to a subject which is of considerable importance in any discussion of world hunger. This is the question of nutrition. Since nutrition is still a relatively new science, nutritionists tend to be regarded as a class apart.' (Boerma, 1975).

Thus nutrition is slipped in at the end, in spite of the fact that the improvement of nutrition was originally given the first priority when FAO was founded, as shown by this extract from the preamble to the constitution of FAO:

'The Nations ... determined to promote the common welfare ... for the purpose of:

raising levels of nutrition and standards of living of the peoples under their respective jurisdictions...

hereby establish the Food and Agriculture Organization of the United Nations' (FAO, 1978).

Recently the Director-General of the World Health Organization was reported to have made the following pronouncement at a meeting in New Delhi of what he expected of us nutritionists:

'One of the reasons for the lack of progress was the fact that nutritionists often failed to understand the socio-economic conditions of the people and their relationship to the problem of nutrition. He stressed the need for a multidisciplinary co-ordinated organized approach to solve the global problem of malnutrition and called for meaningful action through political will and technical management.' (WHO, 1979).

For me such an exhortation, so different from the sharp, clear prose of Boyd Orr, does nothing to point the way ahead. The attitudes of the organizations are, of course, determined in the long run by the political will of their governing bodies and are reflected in their budgets. The values in Table $\mathrm{I}$ give some indication of the importance attached to nutrition. To be fair, many other activities of both organizations impinge on nutrition, but in neither is a full division devoted to the subject. 
Table I. Support for nutrition by UN organizations

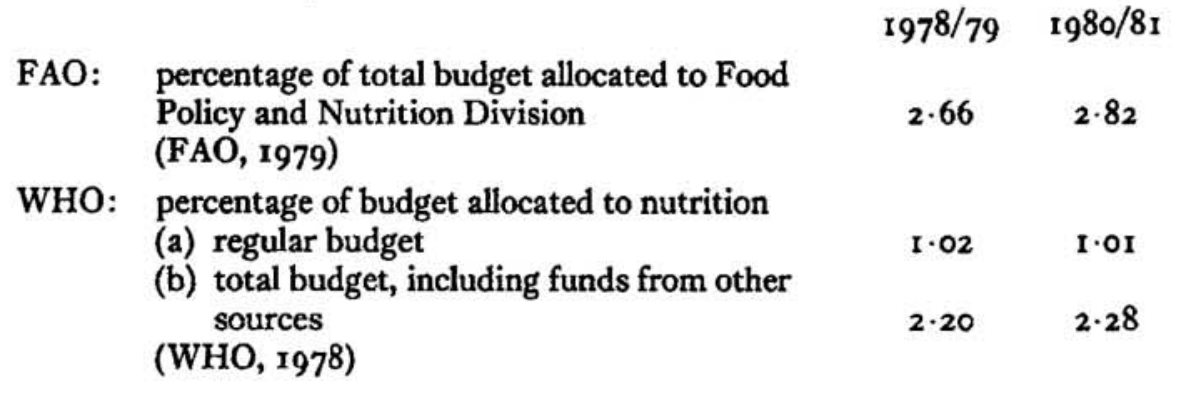

\section{Nutrition as a profession}

In one of the most important meetings of this Society in recent years-Priorities in Research-Rivers (1979) made the point that, 'We cannot consider the future of the science of nutrition without considering the nature of the profession as well.' The distinction between the science or subject and the profession is very apt. I have spoken of the nutritionist being pulled in various directions in trying to establish his scientific identity. Even if he succeeds in this, what are his professional prospects? A profession in the strict sense, as opposed to an occupation, exists because society has a need for people to do a particular kind of work, and it requires evidence that they are qualified to do it. Conversely, a profession has no real existence unless the needs of society are expressed in concrete form as jobs and a career structure. We have neither of these things in nutrition: we have no recognized or required qualifications, other than those for dietitians, and in this country virtually no career structure, except in a handful of university departments and research institutes. It is different in some developing countries, where there is a recognized need for nutritionists at all levels from the village to the central departments of government. The need is no doubt less in this country, but I believe that it exists in many sectors of activity. It is part of the crisis I am speaking about that there is no relationship between existing demand and real needs. It is our job to define those needs, as a first step towards establishing nutrition as a profession.

\section{What is to be done?}

We are faced with a challenge to define our contribution and our role, and I can but expose my own ideas on how to meet it. No-one would dispute the view that improvement in nutrition is dependent upon social and economic change. The kind of improvements for which Boyd Orr fought and which he witnessed in Britain in his own lifetime occurred during a period of increasing real wealth in industrialized countries. As we all know, this period of expansion is coming to an end, and there will be ever greater constraints on the availability and use of the world's resources. A recent report on social inequalities in health in this country (Department of Health and Social Security, 1980) shows, among other things, that the infant mortality rate in social class $\mathrm{V}$ is 2.5 times, and the post-neonatal rate 4.5 times that in class I, so that the work begun by Food, Health and Income is not yet 
finished. It is estimated that to put the inequalities right would cost $£ 2,000$ million, and the Government has said that expenditure of this order cannot be contemplated. All governments, whatever their politics, are faced with the fact that they cannot do everything which ought to be done. With limited resources the choice of priorities is, of course, a political matter, but if the choice is to be in any way rational it has to be based on accurate knowledge.

Boyd Orr said in 1937 , in a lecture to the British Association, 'The starting point for planning in the production and marketing of food is the requirements for an adequate diet' (Orr, 1937). The same point was re-echoed in the introductory paragraphs of the Neuberger report (ARC/MRC, 1974). To many this may seem a conventional and limited approach. Yet the converse of defining an adequate diet is defining what constitutes malnutrition. To me this presents immense challenges, which I will illustrate by two examples.

Energy requirements. Several excellent studies have shown that in some communities in Third World countries average energy intakes are much lower than the requirements proposed by WHO and FAO. The gap seems to be particularly large for lactating women, as Table 2 shows. Intakes of women in the Gambia and New Guinea are approximately $6.3 \mathrm{MJ} / \mathrm{d}(1500 \mathrm{kcal} / \mathrm{d})$ whereas the study of Thomson et al. (1970) in Newcastle (Table 3) shows an average intake of II.3 MJ/d (2700 kcal/d) fitting very well with the conventional estimates of requirements. Of course, the intake measurements in the developing countries may be wrong, but I do not think this can be the whole story. Secondly, it may be argued that the official estimates of requirements may be unrealistic because they are based on observed intakes in developed countries. However, they fit well with actual measurements of energy expenditure, as was shown by Orr \& Leitch (1938) when they reviewed this subject more than forty years ago, and this conclusion has been confirmed by a great deal of work since then, much of it done in Scotland by Durnin and Passmore.

Table 2. Examples of energy intakes and requirements of lactating women

(Values are averages for a group)

$\begin{array}{lll}\text { The Gambia (Paul } \text { et al. } \text { 1979) } & \begin{array}{c}\text { Intakes } \\ \text { MJ (kcal)/d }\end{array} \\ & \begin{array}{l}\text { Maximum } \\ \text { In rains }\end{array} & \begin{array}{c}7.94(1890) \\ 5 \cdot 75(1370)\end{array} \\ \text { Tanzania (Maletnlema \& Bavu, 1974) } & 7 \cdot 76(1847) \\ \text { New Guinea (Norgan } \text { et al. 1974) } & \text { Kaul tribe } & 5.93(1412) \\ & \text { Lufu tribe } & 8.96(2133) \\ & \text { Requirements } \\ \text { FAO/WHO (1973) } & 10 \cdot 71(255)^{\circ} \\ \text { Indian Council of Medical Research (1968) } & 12 \cdot 18(2900)\end{array}$

"Calculated for a woman weighing $45 \mathrm{~kg}$, moderately active, who has not laid down fat during pregnancy. 
Table 3. Energy intakes of women approximately 2 months after childbirth*

\author{
Intake MJ (kcal)/d \\ Lactating (A) Bottle-feeding (B) A-B \\ II.40(2716) $8.92(2125) \quad 2.48(59 \mathrm{I})$ \\ Estimated energy value of breast milk: $\quad 2 \cdot 50(597)$ \\ •From Thomson et al. 1970.
}

All these estimates of requirements are averages, and here, perhaps, the catch lies. The classical studies of Widdowson (1962) showed that the intakes of healthy active people cover at least a two-fold range. It might, therefore, be argued that the women in the Gambia and New Guinea who manage to survive and lactate on these low intakes are all in the lower half of Widdowson's normal range, perhaps as a result of some process of biological selection. However, the physiological problem still remains, of how they-or indeed anyone else-can manage on such intakes. Recent work (Rothwell \& Stock, 1979; Jung et al. 1979) suggests that some individuals can dispose of surplus energy by increasing the oxidative activity of brown fat. Is it possible, by shutting down brown fat altogether, to conserve enough energy so that we come into the lower end of the range of requirements? Or is it necessary to postulate some other mechanism for increasing the thermodynamic efficiency of chemical and physical work in the body? We do not know, and it seems to me very important that we should know. For example, FAO (1977) has suggested that the borderline for malnutrition in adults might be an energy intake less than $\mathrm{I} \cdot 2$ times the standard basal metabolic rate, and on this basis attempts have been made to estimate the number of malnourished people in the world. The resulting figures are useful for comparative purposes, but they have little absolute value until we can answer the fundamental physiological questions. This, therefore, is a subject where there is a pressing need for basic scientific work.

Stunting. A great many children in developing countries, if they survive their first year of life, are retarded in linear growth by comparison with our standards, yet they are of normal weight for height. The stunting becomes progressively commoner as they move from infancy to the toddler age (Waterlow \& Rutishauser, 1974). Fig. I is an excellent example of this progression. I believe myself that it is appropriate to use Western standards for the assessment of growth in Third World countries. The stunting is less marked in children of more affluent groups and it is reversible if conditions improve. Therefore I agree with Habicht that these stunted children are not fulfilling their real growth potential (Habicht et al. 1974). However, even if this is so, does it matter? As Dr Isobel Leitch has pointed out, in most cultures, certainly in our own, the admired person is tall and long-legged (Leitch, I95I). The following quotation from Thackeray is a good example of this attitude: 'I say to you (the reader) that you are better than a Frenchman. I would lay even money that you who are reading this are more than five feet seven in height and weigh eleven stone, while a Frenchman is five feet four and does not 

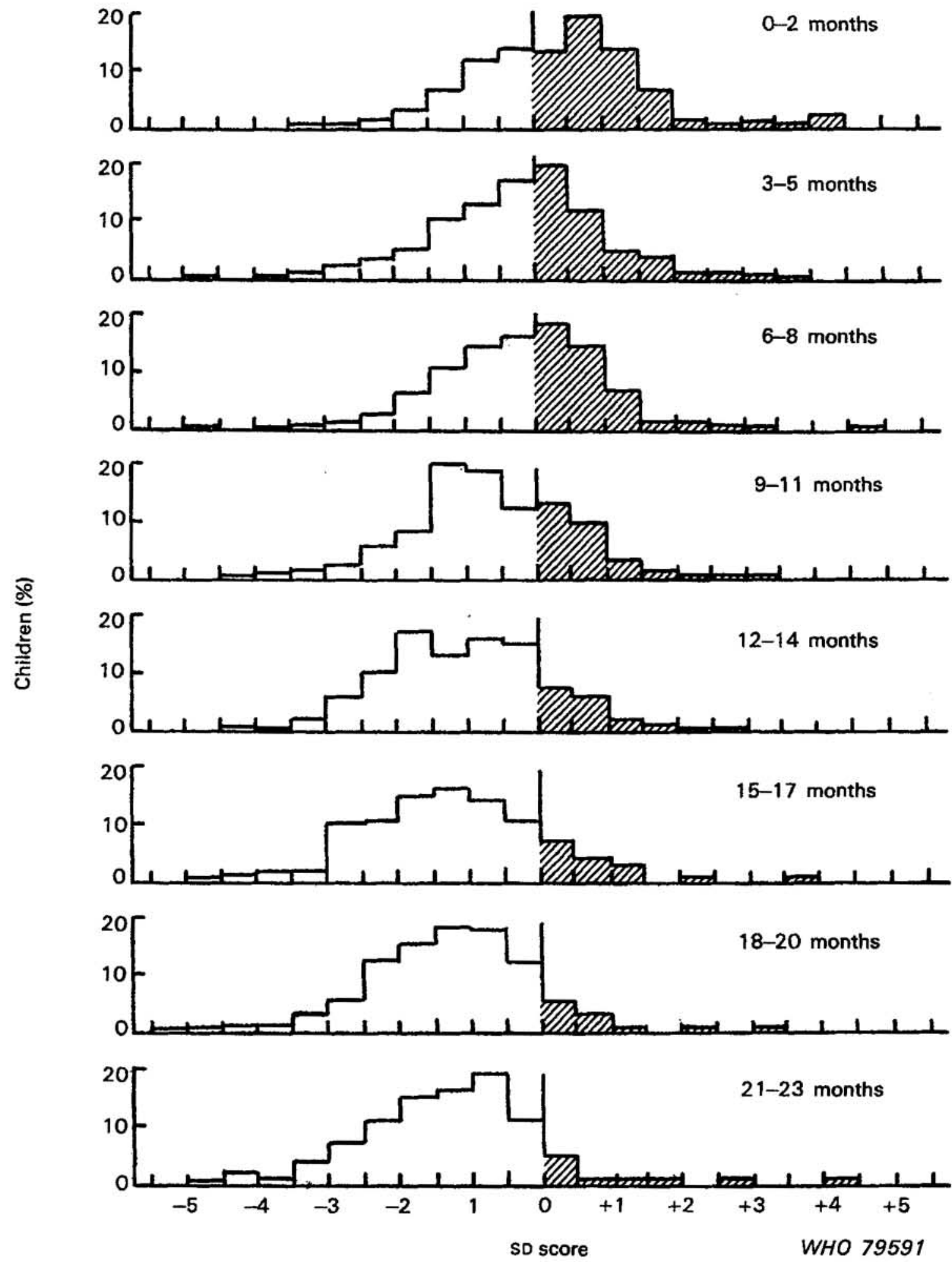

Fig. I. Distribution of height for age in Palestinian refugee children (United Nations General Assembly, 1979). 
weigh nine. The Frenchman has after his soup a dish of vegetables, whereas you have one of meat.' With reference to Thackeray's first sentence, I noticed that Boyd Orr, in his lecture on the 'Role of the Rebel in Society' (1951) said: 'Personally, after a struggle, as the supreme heresy, I even doubt whether a Scotsman is worth two Englishmen.'

Can we dismiss this attitude to height-that taller is better-as jingoism and the snobbishness of the glossy magazines? It has often been suggested that stunting is a useful adaptation, because smaller people need less food. It is true that stunting is a hallmark, what is now called a 'proxy indicator', of adverse social and environmental conditions. Social class differences in height still exist in this country, although they are much smaller than they used to be. It is true also that many studies in the Third World have shown that physical stunting is associated with impaired mental development. Grantham-McGregor (personal communication) has found that a reduction in developmental quotient is much more closely associated with stunting than with the oedematous form of malnutrition classified as kwashiorkor. However, it is very difficult to prove that malnutrition per se is a specific causal factor. Some people would say that this is irrelevant; that if the environment is deprived it must be put right as a whole. It seems to me, however, that if resources are limited it is necessary to identify the risk factors as closely as possible. We need to know whether stunting matters. In many surveys in developing countries some $50 \%$ of pre-school children are described as 'malnourished', based on deficits in weight for age. From two years onwards most of these deficits arise from stunting. If stunting were regarded as an adaptation, or like a kind of healed scar, and therefore unimportant; and if the definition of malnutrition were based only on deficit of weight for height, our estimates of the number of malnourished children in the world would be cut at a stroke by something like $80 \%$ (Table 4 ). Of course, these children would still be underprivileged and in no way do I mean to imply that I regard their condition as satisfactory. However, the question which we have to ask as scientists is: where should the effort be applied? I consider, therefore, that the natural history of stunting - its causes and sequelae - is a subject which should have a top priority for nutritional science.

Both these examples I have given involve the concept of adaptation. To define adaptation is very difficult. The idea obviously involves several elements: metabolic adjustments, social responses and the capacity to take advantage of inborn genetic variability. One also has to approach the concept with caution, because there is always a tendency to say 'I am normal but you are adapted'. Barnicott (1955) put this point very well:

'Primitive peoples often possess remarkable skills and features of social organization which enable them to survive under very severe conditions; to undervalue their capacities is a wasteful attitude to the store of wealth represented by human variation.'

Different states of adaptation must involve both gains and losses, which can only be assessed by measurements of functional capacity in a particular 
Table 4. Proportion of malnourished children in Nepal and Sri Lanka

\author{
Children in sample \\ described as malnourished (\%) \\ Criterion of malnutrition \\ Wasted‡, stuntedll and wasted + stunted \\ Wasted and wasted + stunted \\ Nepal* \\ $56 \cdot 2$ \\ $7 \cdot 3$ \\ Sri Lanka $†$ \\ $38 \cdot 1$ \\ $6 \cdot 7$ \\ -From Brink et al. (1976). \\ †From Brink et al. (1978). \\ $\ddagger$ Defined as less than $80 \%$ of reference median. \\ IIDefined as less than $90 \%$ of reference median. \\ Reference population: National Centre for Health Statistics (1977).
}

environment. This brings us, in fact, to the assessment of nutritional health-the other side of the coin from malnutrition. Boyd Orr, in his lecture in 1937 to the British Association, said:

'There has been a good deal of futile discussion as to the physical measurements and clinical signs which should be regarded as the indication of a suitable standard of health. The only way to determine the proper standard is to go on improving the diet so long as the improvement is followed by an improvement in health ... Anything below that level should be regarded as malnutrition.'

It is, of course, very hard to define and measure 'improvement in health', but there are many people working in nutrition who are right up at the front in this endeavour, in studies on mental development, physical performance, resistance to infection, and so on. This kind of work forms the essential basis of efforts to improve positive health, and I believe that we in nutrition are leading the way.

I have put the case, with which you may or may not agree, that the subject of human nutrition and the people working in it are facing a crisis of identity. In trying to define our role and our response to this crisis I do not want to claim either too much or too little. I claim that there are many problems of great importance for human welfare, which the nutritionist is specially equipped by his training and outlook to define and to tackle. Of course we cannot solve these problems without the help of other disciplines. Nutrition occupies a middle place in the continuous chain of knowledge and endeavour which stretches from molecular biology to social and political science. I have carefully avoided using the word 'central' because that implies a degree of self-importance. Middle is better. My concept is a little different from that of Garry (1955), whom I quoted earlier, of nutrition as a meeting place; this seems to me too negative and too passive. Nutrition has something of its own to offer and in addition, its job is actively to pull together, to connect and to reduce the fragmentation of the biological and social sciences.

Being an optimist, I believe that if we see our purpose and identity clearly, nutrition as a profession will come to be recognized by the community, and we will be able to surmount the problems which face us today. Boyd Orr was an optimist, in spite of setbacks, as is abundantly clear from his writings. The fundamental 
point is to believe, to have faith, that it is actually possible to achieve something, whatever the difficulties, and to combine this faith with humility. Reading Boyd Orr's work I have found my own faith very much fortified. On humility, I cannot do better than end by quoting another great man outstanding for his courage and optimism, Winston Churchill:

'There is no diet so stimulating or so nourishing as to eat one's own words.'

\section{REFERENCES}

ARC/MRC (1974). Food and Nutrition Research. London: HMSO.

Barnicott, N. A. (1955). Biology 20, I.

Blaxter, K. L. (1979). Proc. Nutr. Soc. 38, 213.

Boerma, A. H. (1975). Proc. Nutr. Soc. 34, 146.

Brink, E. W., Khan, J. H., Splitter, J. L., Staehling, N. W., Lane, J. M. \& Nichaman, M. Z. (I976). Bull. Wld Hlth Org. 54, 3 Ir.

Brink, E. W., Perera, W. D. A., Huff, N. R., Staehling, N. W., Lane, J. M. \& Nichaman, M. Z. (1978). Int. F. Epidemiol. 7, 4I.

Correa, G. (1977). Proc. Nutr. Soc. 37, 141.

Department of Health and Social Security (1980). Inequalities in Health. Report of a Research Working Group. London: DHSS.

Economic Advisory Council (1939). Nutrition in the Colonial Empire. London: HMSO.

FAO (1977). The Fourth World Food Survey. FAO Food \& Nutrition Ser. no. Io. Rome: FAO.

FAO (1978). Basic Texts of the Food and Agriculture Organization of the United Nations. Rome: FAO.

FAO (1979). Director-General's Programme of Work and Budget for 1980/81. Rome: FAO.

FAO/WHO (1973). Energy and Protein Requirements. Report of a Joint FAO/WHO Ad hoc Expert Committee. FAO Nutrition Meetings Rep. Ser. no. 52. Rome: FAO.

Garry, R. C. (1955). Proc. Nutr. Soc. 12, 270.

Habicht, J-P., Martorell, R., Yarbrough, C., Malina, R. M. \& Klein, R. E. (1974). Lancet i, 6r1.

Indian Council of Medical Research (1968). Recommended Daily Allowances of Nutrients and Balanced Diets. Hyderabad: Nutrition Research Laboratories, ICMR.

Jung, R. J., Shetty, P. S., James, W. P. T., Barrand, M. \& Callingham, B. A. (1979). Nature, Lond. 279, 322 .

Kay, H. D. (1972). Biographical Memoirs of Fellows of the Royal Society. p. 43.

Leitch, I. (I95I). Proc. Nutr. Soc. 5, 142.

Maletnlema, T. N. \& Bavu, J. L. (1974). E. Afr. med. F. 51, 515.

National Center for Health Statistics. (1977). NCHS Grovoth Curves for Children, Birthr8 Years. United States. Publication no. (PHS) 78-1650. US Department of Health Education and Welfare.

Norgan, N. G., Ferro-Luzzi, A. \& Durnin, J. V. G. A. (1974). Phil. Trans. R. Soc. Ser. B. 268, 309.

Orr, J. B. (1928). Lancet i, 202.

Orr, J. B. (1934). The National Food Supply and its Influence on Public Health. Chadwick Lecture. London: P. S: King \& Sons.

Orr, J. B. (1935). The Economics of Diet. Rep. Br. Assoc. September.

Orr, J. B. (1936). Food, Health and Income. A Report on a Survey of Adequacy of Diet in Relation to Income. London: Macmillan \& Co.

Orr, J. B. (1937). In What Science Stands For. London: George Allen \& Unwin.

Orr, J. B. (r951). The Role of the Rebel in Society. Maxton Memorial Lecture. London: James Maxton Memorial Committee.

Orr, J. B. \& Gilks, J. L. (1927). Lancet i, 560.

Orr, J. B. \& Gilks, J. L. (1931). Spec. Rep. Ser. med. Res. Coun. no. 555 . London: HMSO.

Orr, J. B. \& Leitch, I. (1938). Nutr. Abstr. Rev. 7, 509.

Paul, A. A., Muller, E. M. \& Whitehead, R. G. (1979). Trans. R. Soc. trop. Med. Hyg. 73, 686.

Rivers, J. (1979). Proc. Nutr. Soc. 38, 225. 
Vol. 40

Rothwell, N. J. \& Stock, M. J. (1979). Nature, Lond. 281, 3 r.

Thomson, A. M. (1978). Proc. Nutr. Soc. 37, 317.

Thomson, A. M., Hytten, F. G. \& Billewicz, W. Z. (1970). Br. f. Nutr. 24, 565.

United Nations General Assembly (1979). Health Needs of Palestinian Refugees. Document $\mathrm{A} / 34 / 463$.

Waterlow, J. C. \& Rutishauser, I. H. E. (1974). In Early Malnutrition and Mental Development, p. 13 [J. Cravioto, L. Hambraeus and Bo Vahlquist, editors]. Stockholm: Almqvist \& Wiksell.

WHO (1978). Proposed Programme Budget for the Financial Period 1980/8r. Geneva: Official Records of the World Health Organization.

WHO (1979). An Action Research Programme for Nutrition in Developing Countries. WHO S.E. Asia Regional Office. New Debli.

Widdowson, E. M. (1962). Proc. Nutr. Soc. 21, 121.

Williams, C. D. (1935). Lancet ii, Ir5r. 